Proceeding Paper

\title{
A Comparative Case Analysis of Meteorological and Air Pollution Parameters between a High and Low Port Activity Period in Igoumenitsa Port ${ }^{\dagger}$
}

\author{
Ioannis Logothetis ${ }^{1, * \mathbb{D}}$, Christina Antonopoulou ${ }^{1}$, Konstantinos Sfetsioris ${ }^{2}$, Adamantios Mitsotakis ${ }^{1}$ \\ and Panagiotis Grammelis ${ }^{1}$ (D)
}

1 Centre for Research and Technology Hellas, Chemical Process and Energy Resources Institute, Thermi, GR 57001 Thessaloniki, Greece; antonopoulou@certh.gr (C.A.); adamis@certh.gr (A.M.); grammelis@certh.gr (P.G.)

2 Hellenic Association of Energy Economics, 14562 Athens, Greece; sfetsioris@certh.gr

* Correspondence: logothetis@certh.gr

+ Presented at the 2nd International Electronic Conference on Applied Sciences, 15-31 October 2021; Available online: https://asec2021.sciforum.net/.

Citation: Logothetis, I.; Antonopoulou, C.; Sfetsioris, K.; Mitsotakis, A.; Grammelis, P. A Comparative Case Analysis of Meteorological and Air Pollution Parameters between a High and Low Port Activity Period in Igoumenitsa Port. Eng. Proc. 2021, 11, 33. https://doi.org/10.3390/ ASEC2021-11118

Academic Editor: Nunzio Cennamo Published: 15 October 202

Publisher's Note: MDPI stays neutral with regard to jurisdictional claims in published maps and institutional affiliations.

Copyright: (C) 2021 by the authors. Licensee MDPI, Basel, Switzerland. This article is an open access article distributed under the terms and conditions of the Creative Commons Attribution (CC BY) license (https:// creativecommons.org/licenses/by/ $4.0 /)$

\begin{abstract}
Among the most important trade bridges for Western Europe and the Balkans is the Port of Igoumenitsa in Western Greece, which experiences heavy traffic of goods and passengers. This case analysis primarily aims to investigate the effect of shipping and port operations on air quality in the Port of Igoumenitsa, comparing two representative short case seasons of air quality measurement campaigns. The high activity season ranges from 25 to 31 August 2018, while the low season ranges from 17 to 25 May 2018. A mobile air quality monitoring system was used to perform the analysis. To compare the air quality of the examined periods, the wind speed rose diagrams, the correlation analysis, as well as the hourly variations in concentrations of pollutants and meteorological parameters, were studied. In addition, the impact of meteorology and atmospheric circulation on local air quality were investigated. For study implementation, various types of data, obtained from NASA Worldview application, Barcelona Supercomputing Center (BSC), and Giovanni online system (NASA-GES-DISC) were included. The results indicate that port operations affect the air quality in the Port of Igoumenitsa, as the high season showed higher concentrations of air pollutants compared to the low season. A notable exception was the concentration of PMs, which was affected by an African dust transfer event during the low season. Finally, the findings indicate that climatic factors affect the pollution levels of the case analysis, and emphasize the importance of developing a green and sustainable management system within the port.
\end{abstract}

Keywords: air quality; shipping; port activity; climate; meteorology; synoptic atmospheric circulation; African dust transfer; eastern Mediterranean; green and sustainable port management

\section{Introduction}

The port activities and shipping are a major source of pollutants for the coastal areas, affecting not only air quality and its degradation [1,2] but also human health [3,4]. Although the port-related pollutants are not the dominant source of marine pollution, they are related to health problems and have an impact on mortality levels [5,6]. In particular, it turns out that human health problems are associated with exposure to $\mathrm{PM}_{2.5}$ emitted by shipping [1,7]. Evidently, emissions from shipping contribute significantly to the $\mathrm{NO}_{\mathrm{x}}$ $\mathrm{SO}_{2}$, and PM concentrations over port and coastal regions, while between 2007 and 2012, shipping accounted for about 1 billion tons of GHGs [8]. The IMO's 4th Greenhouse Gas Study [9] projected that the GHGs shipping emissions will increase up to 50\% by 2050 compared to the 2018 levels. Consequently, increasing shipping and port activities contribute to climate change [10]. In particular, the increased concentration of pollutants 
in the atmosphere affects the weather and climate [11], producing positive climate forcing and enhancing the climate risk.

The atmospheric circulation is also a significant factor that affects the air quality [2,7]. The transfer and transformation of pollutants from Europe as well as the mineral dust from North Africa affect the pollution levels of the southeastern Mediterranean [12]. In particular, the peak of dust transfer is usually identified during the autumn and spring season affecting the concentration of PMs [13]. Finally, dust episodes have an impact on the climate since they modify the albedo and solar radiation on the earth's surface [12].

The port of Igoumenitsa is an important trade hub between Western and Eastern Europe, which connects the main Italian ports with Western Greece. About 1.5 million passengers and 140,000 trucks move through the port each year. Based on the lack of studies regarding the effect of shipping and atmospheric features (meteorology and synoptic atmospheric circulation) on the air quality in Western Greece, this analysis seeks to fill this gap. A comparison of the two seasons is characterized by the high and low port activity, respectively. Finally, this study highlights the importance of a larger measurement campaign in order to further improve the knowledge regarding the impact of shipping on the coastal port region of Igoumenitsa.

\section{Methods and Data}

Igoumenitsa $\left(39.50615^{\circ} \mathrm{N}, 20.265534^{\circ} \mathrm{E}\right)$ is located in Western Greece (Figure 1) and it is a commercial hub for Southeastern Europe. The port of the city has high trade activity as a large number of passengers, cars, and trucks use it on an annual basis. A mobile air quality monitoring station, equipped with ambient air pollution sensors (HORIBA sensors) and in accordance with the EN regulations for certified measurements, was employed at the port of Igoumenitsa. Sensor recordings include meteorological parameters (wind direction-WDir; ${ }^{\circ}$, wind speed-WS; $\mathrm{m} / \mathrm{s}$, temperature $-\mathrm{T} ;{ }^{\circ} \mathrm{C}$, relative humidity; $\mathrm{RH}-\%$, pressure- $\mathrm{P} ; \mathrm{hPa})$, particle matters $\left(\mathrm{PM}_{1}, \mathrm{PM}_{2.5}, \mathrm{PM}_{4}, \mathrm{PM}_{10}, \mathrm{PM}_{-}\right.$tot; $\left.\mu \mathrm{g} / \mathrm{m}^{3}\right)$, and gases (CO; ppm, $\mathrm{NO} ; \mathrm{ppb}, \mathrm{NO}_{2} ; \mathrm{ppb}, \mathrm{NO}_{x} ; \mathrm{ppb}, \mathrm{O}_{3} ; \mathrm{ppb}, \mathrm{SO}_{2} ; \mathrm{ppb}$ ).

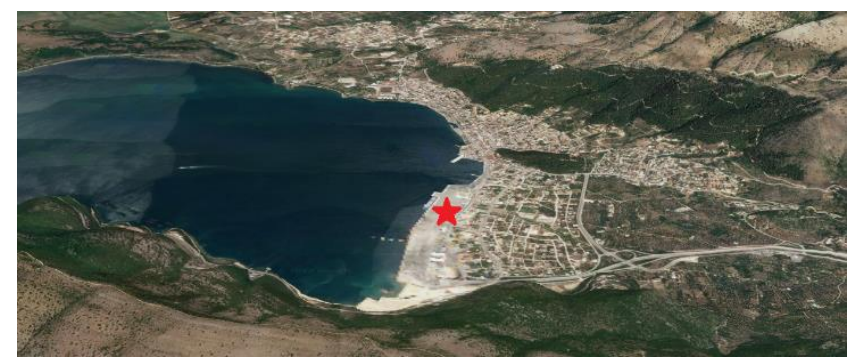

Figure 1. The location of the mobile air quality monitoring station in Igoumenitsa port (red star).

To study the impact of harbor operation in the port of Igoumenitsa during 2018, two cases were examined. The first case, with high port activity (HS), is considered the period from 25 to 31 August 2018, and the second, with low port activity (LS), is from 17 to 25 May 2018. In order to investigate the relation between the meteorology and concentration of pollutants, the Spearman correlation is employed for both studied seasons. Moreover, the hourly variation of meteorology parameters and concentration of pollutants are calculated to study the effect of hourly port activity during the two seasons. To examine the effect of synoptic atmospheric circulation on concentrations of PMs in the port, a satellite image provided by NASA Worldview application is also used (Figure 2a). Additionally, a figure provided by the DREAM8b model, operated by the Barcelona Supercomputing Center, is shown (Figure 2b). Results from MERRA-2 model version 2 (M2T1NXAER v5.12.4), available from the Giovanni online data system generated by NASA Goddard Earth Sciences (GES) Data and Information Services Center (DISC) [14], are also included in the analysis. Finally, the $\mathrm{PM}_{2.5} / \mathrm{PM}_{10}$ ratio $\left(R_{P M}\right)$ is usually used to characterize the origin of pollutants (the anthropogenic or natural sources) [2,15]. In order to investigate 
the impact of shipping traffic and port operations (anthropogenic activities) in the port of Igoumenitsa, the $R_{P M}$ is calculated for both case seasons (HS and LS).

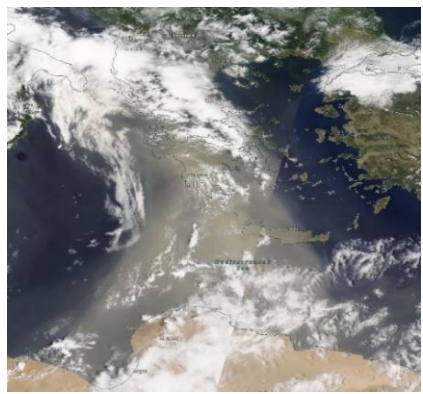

(a)

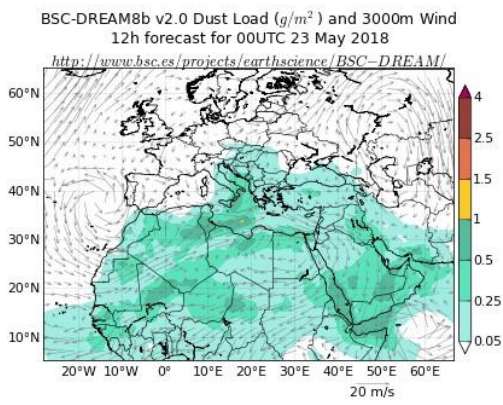

(b)

Figure 2. (a) Image of African dust transport in Greece on 23 May 2018 (MODIS visible imagery). (b) Dust load and $3000 \mathrm{~m}$ wind speed for 23 May 2018, (BSC-DREAM8b).

\section{Results}

Figure 3 shows the wind-rose plot for the two studied periods, where the wind speeds are stronger in the LS (compared to HS) and blow mainly from the western sector, as well as the eastern directions for the HS and LS, respectively.

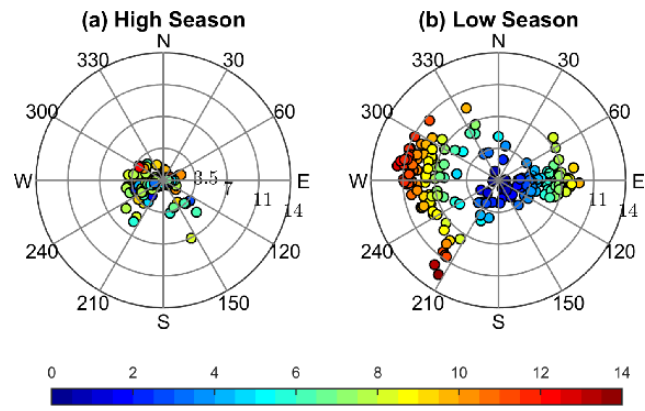

Figure 3. Wind-rose plot for (a) high port activity season (HS) and (b) low port activity season (LS).

The relation (negative correlation) of the wind speed with the concentration of pollutants indicates that higher winds tend to reduce the concentration for the majority of pollutants $\left(\mathrm{PM}_{10}, \mathrm{PM}_{\mathrm{tot}}, \mathrm{CO}, \mathrm{NO}_{2}\right.$, and $\left.\mathrm{NO}_{\mathrm{x}}\right)$. The wind speed is positively correlated with the $\mathrm{O} 3$ concentration since the $\mathrm{O} 3$ concentration is affected by photochemical reactions during the sunlight hours [11]. Additionally, the concentration of $\mathrm{O} 3$ is significantly negatively correlated (about -0.65 ) with $\mathrm{NO}_{2}$ and $\mathrm{NO}_{\mathrm{x}}$. To conclude, the analysis shows that meteorological conditions significantly affect the air quality $[16,17]$.

Figure 4 shows the hourly variation of meteorology parameters (Figure $4 a-e$ ) and the concentration of pollutants (Figure $4 \mathrm{f}-\mathrm{p}$ ) for both studied seasons. The analysis shows that the concentration of pollutants is maximized during the hours with high ship traffic (7:00-11:00 LT and 19:00-24:00 LT) indicating that harbor operations degrade the air quality in the port of Igoumenitsa. Comparing the two seasons studied, the $\mathrm{O}_{3}$ and $\mathrm{NO}_{x}$ concentrations increased by about $10 \mathrm{ppb}$ for HS. Additionally, the concentrations of $\mathrm{NO}_{2}$ and $\mathrm{SO}_{2}$ are increased $\sim 2.5 \mathrm{ppb}$ for the HS in comparison to the LS. Moreover, during the HS, the concentration of $\mathrm{PM}_{1}$ is increased $\sim 2.5 \mu \mathrm{g} / \mathrm{m}^{3}$, while in contrast, the concentration of $\mathrm{PM}_{4}$, as well as $\mathrm{PM}_{10}$, is reduced $\sim 5.5 \mu \mathrm{g} / \mathrm{m}^{3}$. The positive difference of $\mathrm{PM}_{4}$ and $\mathrm{PM}_{10}$, between HS and LS, is explained by the synoptic atmospheric circulation. In particular, it must be stated that the Saharan dust is a major component for $\mathrm{PM}_{10}$ over the Mediterranean basin [18]. Previous studies have shown that the concentration of $\mathrm{PM}_{10}$ is maximized mainly during the transitional seasons (autumn and spring) [19]. In particular, for the 
Heraklion and Athens (Greece), the concentration of $\mathrm{PM}_{10}$ is maximized in April during 2003-2006, which is possible due to the dust transport [12,13]. During the low port activity season, the African dust transfer event affects the eastern Mediterranean and the Western Greece and peaks on 23 May 2018 (Figure 2a,b). Furthermore, the results of the analysis of MERRA-2 model (available from the Giovanni data system) indicate that during the LS the difference of mean dust column mass density $\left(\mathrm{gr} / \mathrm{m}^{2}\right)$ increases compared to the high season, affecting the PM concentrations (mainly $\mathrm{PM}_{10}$ and $\mathrm{PM}_{4}$ ) over Western Greece and the port of Igoumenitsa (Figure 5).

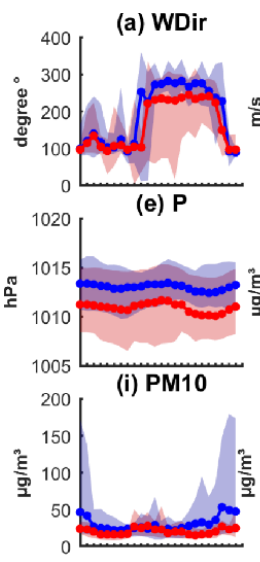

(m) NO (b) WS

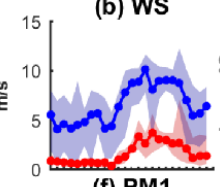

(f) PM1

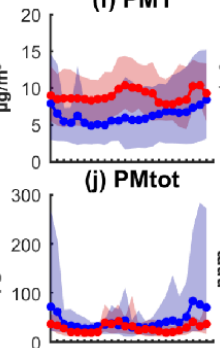

(n) NO2

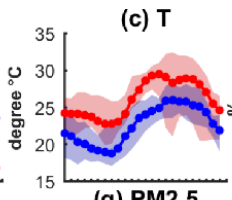

(g) PM2.5

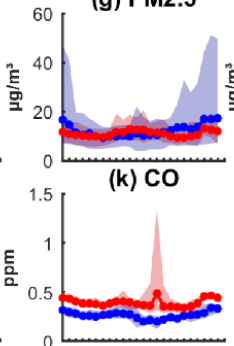

(o) NOx
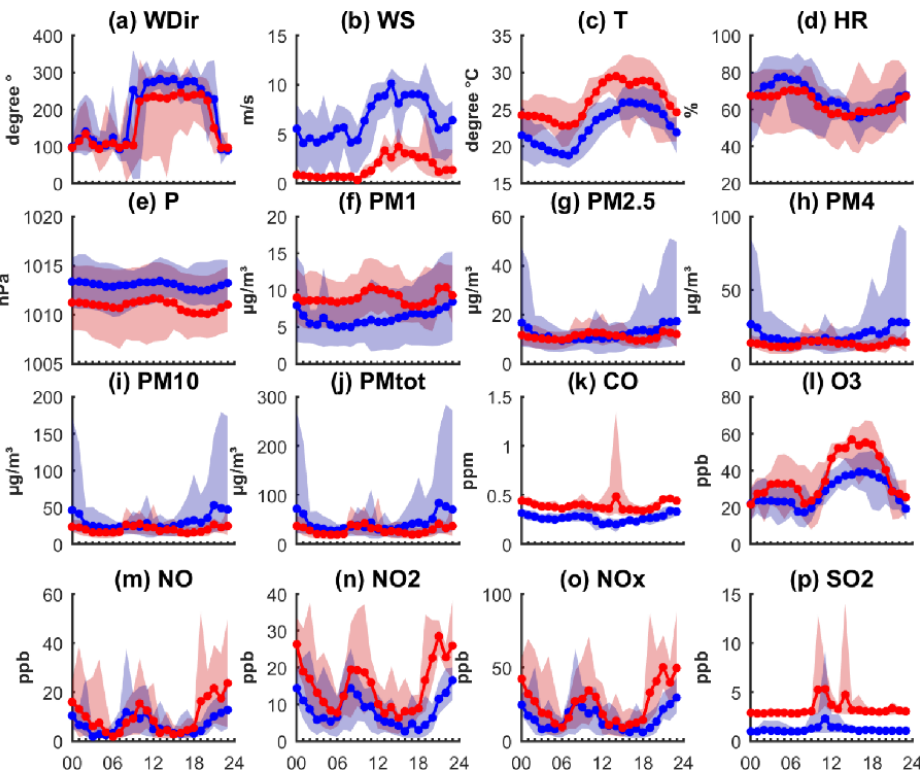

(p) SO2

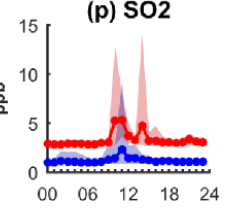

Figure 4. Mean diurnal variation of meteorology factors (a-e) and air quality parameters $(\mathbf{f}-\mathbf{p})$. The red/blue lines show the high/low port activity season. The colored regions are the range between the lower and higher hourly variability at every hour of the season.

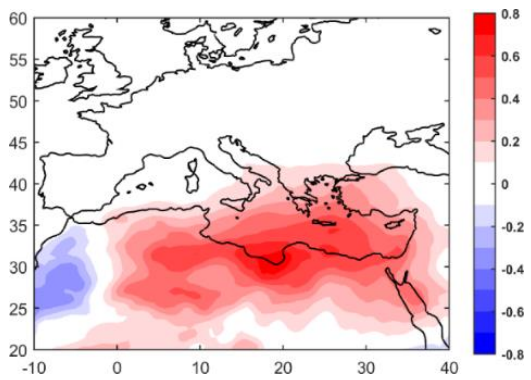

Figure 5. Composite difference of mean dust column mass density $\left(\mathrm{gr} / \mathrm{m}^{2}\right)$ between the low port activity and high port activity season. Red/blue colors indicate an increase/decrease of the mean dust column mass density $\left(\mathrm{gr} / \mathrm{m}^{2}\right)$.

In general, human activities and meteorological conditions are important factors that affect the ratio between $\mathrm{PM}_{2.5}$ and $\mathrm{PM}_{10}\left(R_{P M}\right)$ [15]. The higher (lower) $R_{P M}$ is more related to anthropogenic (natural) sources [15]. Additionally, the $R_{P M}$ can be used to identify the source of the PMs, indicating whether the pollution is primarily due to anthropogenic or natural activity [2,20]. In order to investigate the impact of harbor operation on Igoumenitsa port, the $R_{P M}$ is calculated. Figure 6 presents the variability of $R_{P M}$ for the two studied seasons. During the HS, the $R_{P M}$ ratio is about 0.13 higher compared to the LS (Figure 6c). Consequently, during the HS, the shipping has a more significant effect on the pollution levels of Igoumenitsa. 

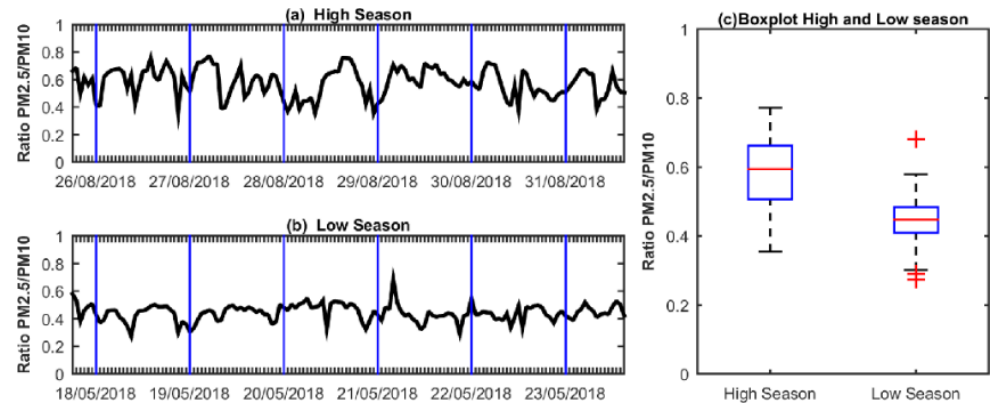

Figure 6. Timeseries of $R_{P M}$ for the (a) high port activity season (HS) and (b) low port activity season (LS). (c) Boxplot of $R_{P M}$ for the high and low port activity season.

\section{Conclusions}

This work examines the effect of shipping and port operation on the pollution levels of Igoumenitsa in Western Greece. The analysis is carried out through a comparison of the high (HS) and low (LS) port activity season during 2018 and the obtained findings indicate that meteorology affects the concentration of pollutants. In particular, wind speed tends to reduce the concentration of the majority of pollutants. For both seasons, the elevated concentration of pollutants occurs during the hours of high shipping traffic. It should be noted that the concentration of pollutants generally increases during the HS. The $\mathrm{PM}_{4}$ and $\mathrm{PM}_{10}$ concentrations are excluded due to the effect of a Saharan dust transfer episode. The aforementioned dust episode occurs during the LS, affecting the PM concentrations over Western Greece. The higher ratio of $\mathrm{PM}_{2.5}$ to $\mathrm{PM}_{10}\left(R_{P M}\right)$ during the HS indicates that the shipping contributes to the increase in the air pollution of Igoumenitsa. The analysis emphasizes that during the studied periods (HS and LS), the shipping and harbor activities affect the air quality of Igoumenitsa. Finally, this case study demonstrates that a further investigation of air quality in the port for a long-temporal period can provide important results, which can help the competent authorities in adopting energy saving practices that reduce air pollution footprint in ports.

Author Contributions: Conceptualization, I.L., A.M. and P.G.; methodology, I.L.; software, I.L.; validation, I.L.; formal analysis, I.L.; investigation, I.L.; resources, I.L.; data curation, I.L.; writingoriginal draft preparation, I.L.; writing-review and editing, I.L., C.A., A.M., K.S.; visualization, I.L.; supervision, A.M. and P.G.; project administration, P.G.; funding acquisition, A.M. and P.G. All authors have read and agreed to the published version of the manuscript.

Funding: This research was funded by the Connecting Europe Facility of the European Union, grant number 2014-EU-TM-0673-S and the APC was funded by Poseidon Med II Action No. 2014-EU-TM-0673-S.

Institutional Review Board Statement: Not applicable.

Informed Consent Statement: Not applicable.

Data Availability Statement: Publicly available datasets were analyzed in this study. These data can be found here: http:/ / www.bsc.es/ess/bsc-dust-daily-forecast/ (accessed on 14 June 2021), https: / / worldview.earthdata.nasa.gov (accessed on 10 June 2021), and https: / giovanni.gsfc.nasa. gov / giovanni/ (accessed on 3 June 2021).

Acknowledgments: The study received support from the POSEIDON MEDII project, which is co-financed by the Connecting Europe Facility (CEF) Transport Sector of the European Union. The authors would like to thank the DEPA Commercial S.A. (project coordinator) and DESFA S.A. (project technical coordinator). In addition, we would like to thank the Igoumenitsa Port Authority S.A. and personnel for providing information regarding the port activity to guarantee the representative sampling of recordings for the analysis. We acknowledge the Envirosys Ltd. Environmental Applications Technological Equipment, Athens, Greece, for the collaboration and the availability of the Horiba Ltd. Sensors. Moreover, the authors would like to acknowledge the (NMMB/BSC-Dust or BSC-DREAM8b) model, operated by the Barcelona Supercomputing Center (http://www.bsc.es/ess/bsc-dust-daily-forecast/) (accessed on 14 June 2021) for 
the provided image. We acknowledge the use of imagery from NASA's Worldview application (https: / / worldview.earthdata.nasa.gov (accessed on 10 June 2021), part of NASA's Earth Observing System Data and Information System (EOSDIS). Part of the analysis used in this study was produced with the Giovanni online data system, developed and maintained by the NASA Goddard Earth Sciences (GES) Data and Information Services Center (DISC) (accessed on 3 June 2021).

Conflicts of Interest: The authors declare no conflict of interest.

\section{References}

1. Tang, L.; Ramacher, M.O.P.; Moldanová, J.; Matthias, V.; Karl, M.; Johansson, L.; Jalkanen, J.-P.; Yaramenka, K.; Aulinger, A.; Gustafsson, M. The impact of ship emissions on air quality and human health in the Gothenburg area-Part 1: 2012 emissions. Atmos. Chem. Phys. 2020, 20, 7509-7530. [CrossRef]

2. Logothetis, I.; Antonopoulou, C.; Sfetsioris, K.; Mitsotakis, A.; Grammelis, P. Comparison analysis of the effect of high and low port-activity season on air quality in the port of Heraklion. In Proceedings of the 4th International Electronic Conference on Atmospheric Sciences, Online, 16-31 July 2021; MDPI: Basel, Switzerland, 2021. [CrossRef]

3. Gobbi, G.P.; Liberto, L.; Barnaba, F. Impact of port emissions on EU-regulated and non-regulated air quality indicators: The case 29 of Civitavecchia (Italy). Sci. Total Environ. 2020, 719, 134984. [CrossRef] [PubMed]

4. Prussi, M.; Scarlat, N.; Acciaro, M.; Kosmas, V. Potential and limiting factors in the use of alternative fuels in the Euro-pean 18 maritime sector. J. Clean. Prod. 2021, 291, 125849. [CrossRef] [PubMed]

5. Viana, M.; Fann, N.; Tobías, A.; Querol, X.; Rojas-Rueda, D.; Plaza, A.; Aynos, G.; Conde, J.A.; Fernández, L.; Fernández, C. Environmental and health benefits from designating the Marmara Sea and the Turkish Straits as an emission control area (ECA). Environ. Sci. Technol. 2015, 49, 3304-3313. [CrossRef] [PubMed]

6. Sofiev, M.; Winebrake, J.J.; Johansson, L.; Carr, E.W.; Prank, M.; Soares, J.; Vira, J.; Kouznetsov, R.; Jalkanen, J.-P.; Corbett, J.J. Cleaner fuels for ships provide public health benefits with climate tradeoffs. Nat. Commun. 2018, 9, 406. [CrossRef]

7. World Health Organization (WHO), Europe. Health Risks of Particulate Matter from Long-Range Transboundary Air Pollution; Joint WHO/Convention Task Force on the Health Aspects of Air Pollution, European Centre for Environment and Health Bonn Office, World Health Organization: Geneva, Switzerland, 2006.

8. Smith, T.W.P.; Jalkanen, J.P.; Anderson, B.A.; Corbett, J.J.; Faber, J.; Hanayama, S.; O’Keeffe, E.; Parker, S.; Johansson, L.; Aldous, L.; et al. Third IMO Greenhouse Gas Study 2014; International Maritime Organization: London, UK, 2015; 327p.

9. International Marina Organization. Fourth IMO GHG Study 2020 Executive Summary; International Maritime Organization: London, UK, 2021.

10. Wang, X.; Shen, Y.; Lin, Y.; Pan, J.; Zhang, Y.; Louie, P.K.K.; Li, M.; Fu, Q. Atmospheric pollution from ships and its impact on local air quality at a port site in Shanghai. Atmos. Chem. Phys. 2019, 19, 6315-6330. [CrossRef]

11. Shilenje, Z.W. Observed surface ozone trend in the year 2012 over Nairobi, Kenya. Atmosfera 2014, 27, 377-384. [CrossRef]

12. Mitsakou, C.; Kallos, G.; Papantoniou, N.; Spyrou, C.; Solomos, S.; Astitha, M.; Housiadas, C. Saharan dust levels in Greece and received inhalation doses. Atmos. Chem. Phys. 2008, 8, 7181-7192. [CrossRef]

13. Kallos, G.; Astitha, M.; Katsafados, P.; Spyrou, C. Long-range transport of anthropogenically and naturally produced particulate matter in the Mediterranean and North Atlantic: Current state of knowledge. J. Appl. Meteorol. Clim. 2007, 46, 1230-1251. [CrossRef]

14. Acker, J.G.; Leptoukh, G. Online Analysis Enhances Use of NASA Earth Science Data. Eos Trans. AGU 2007, 88, 14-17. [CrossRef]

15. Fan, H.; Zhao, C.; Yang, Y.; Yang, X. Spatio-Temporal Variations of the PM2.5/PM10 ratios and Its Application to Air Pollution Type Classification in China. Front. Environ. Sci. 2021, 9, 692440. [CrossRef]

16. Merico, E.; Gambaro, A.; Argiriou, A.; Alebic-Juretic, A.; Barbaro, E.; Cesari, D.; Chasapidis, L.; Dimopoulos, S.; Dinoi, A.; Donateo, A.; et al. Atmospheric im-pact of ship traffic in four Adriatic-Ionian port-cities: Comparison and harmonization of different approaches. Transp. Res. Part D Transp. Environ. 2017, 50, 431-445. [CrossRef]

17. Karagiannidis, A.; Poupkou, T.; Giannaros, C.; Giannaros, D.; Melas, A. Argiriou The air quality of a Mediterranean urban environment area and its relation to major meteorological parameters. Water Air Soil Pollut. 2015, 226, 2239. [CrossRef]

18. Pey, J.; Querol, X.; Alastuey, A.; Forastiere, F.; Stafoggia, M. African dust outbreaks over the Mediterranean Basin during 2001-2011: PM10 concentrations, phenomenology and trends, and its relation with synoptic and mesoscale meteorology. Atmospher. Chem. Phys. 2013, 13, 1395-1410. [CrossRef]

19. Gerasopoulos, E.; Kouvarakis, G.; Babasakalis, P.; Vrekoussis, M.; Putaud, J.P.; Mihalopoulos, N. Origin and variability of particulate matter (PM10) mass concentrations over the Eastern Mediterrane. Atmos. Environ. 2006, 40, 4679-4690. [CrossRef]

20. Zhao, C.; Li, Y.N.; Zhang, F.; Sun, Y.L.; Wang, P.C. Growth rates of fine aerosol particles at a site near Beijing in June 2013. Adv. Atmos. Sci. 2018, 35, 209-217. [CrossRef] 